\title{
Inspiratory duty cycle responses to flow limitation predict nocturnal hypoventilation
}

\author{
H. Schneider, V. Krishnan, L.E. Pichard, S.P. Patil, P.L. Smith and A.R. Schwartz
}

ABSTRACT: Upper airway obstruction (UAO) can elicit neuromuscular responses that mitigate and/or compensate for the obstruction. It was hypothesised that flow-limited breathing elicits specific timing responses that can preserve ventilation due to increases in inspiratory duty cycle rather than respiratory rate.

By altering nasal pressure during non-rapid eye movement (non-REM) sleep, similar degrees of UAO were induced in healthy males and females $(n=10$ each). Inspiratory duty cycle, respiratory rate and minute ventilation were determined for each degree of UAO during non-REM sleep and compared with the baseline nonflow-limited condition.

A dose-dependent increase in the inspiratory duty cycle and respiratory rate was observed in response to increasing severity of UAO. Increases in the inspiratory duty cycle, but not respiratory rate, helped to acutely maintain ventilation. Heterogeneity in these responses was associated with variable degrees of ventilatory compensation, allowing for the segregation of individuals at risk for hypoventilation during periods of inspiratory airflow limitation.

Upper airway obstruction constitutes a unique load on the respiratory system. The inspiratory duty cycle, but not the respiratory rate, determine the individual's ability to compensate for inspiratory airflow limitation during sleep, and may represent a quantitative phenotype for obstructive sleep apnoea susceptibility.

KEYWORDS: Nocturnal hypoventilation, obstructive sleep apnoea, sex, sleep-disordered breathing, susceptibility, ventilatory control

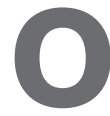
bstructive sleep apnoea comprises a spectrum of patients with varying degrees of upper airway obstruction (UAO) as manifested by snoring with intermittent arousals (upper airway resistance syndrome and respiratory effort-related arousals), obstructive hypopnoeas and apnoeas [1-3]. While male sex and obesity constitute strong risk factors for the varied manifestation of obstructive sleep apnoea [4-6], heritable factors can also play a significant role in the risk of this disorder [7-13], contributing to the heterogeneity in the expression of this disorder. Nevertheless, physiological mechanisms that explain the heterogeneity of sleep-disordered breathing severity are not known.

UAO during sleep plays a pivotal role in the pathogenesis of obstructive sleep apnoea [14] and is caused by structural defects and disturbances in neuromuscular control $[14,15]$. UAO can elicit neuromuscular responses that mitigate and/or compensate for the obstruction. Under conditions of UAO (inspiratory airflow limitation), immediate responses in respiratory timing indices can help restore ventilation [16-19] and blunt disturbances in gas exchange [20]. Nevertheless the impact of respiratory pattern responses on ventilation during periods of $\mathrm{UAO}$ remains unclear.

The purpose of the current study is to examine ventilatory responses to UAO during sleep in normal males and females. It was hypothesised that flow-limited breathing elicits specific timing responses that can preserve ventilation with increases in inspiratory duty cycle $\left(t \mathrm{I} / t_{\text {tot }}\right)$ rather hypothesis, responses to defined levels of UAO were examined that were experimentally imposed in non-rapid eye movement (nonREM) sleep. Responses in $t \mathrm{I} / \mathrm{ttot}_{\mathrm{t}} \mathrm{fR}$ and minute ventilation $\left(V^{\prime} \mathrm{E}\right)$ were evaluated in body mass index (BMI) and age matched normal males and females, and have been partially reported in abstract form [21, 22]. than respiratory frequency $(f R)$. To test this

\section{AFFILIATIONS}

Division of Pulmonary and Critical Care Medicine, Johns Hopkins Sleep Disorders Center, Baltimore, MD, USA.

\section{CORRESPONDENCE}

H. Schneider, Division of Pulmonary and Critical Care Medicine, Johns Hopkins Asthma and Allergy Center, 5501 Hopkins Bayview Circle, Baltimore, MD 21224, USA Fax: 14105502612

E-mail: hschnei3@jhmi.edu

Received:

April 242008

Accepted after revision:

December 032008

SUPPORT STATEMENT

Funded by grants: HL 72126, HL 50381, HL 37379, HL077137 and P50 HL084945-01 from the National Institutes of Health ( $\mathrm{NIH}$; Washington, DC, USA). This publication was also made possible by Grant Number UL1 RR 025005 from the National Center for Research Resources (NCRR; Bethesda, MD, USA), a component of the NIH (Bethesda) and $\mathrm{NIH}$ Roadmap for Medical Research (Bethesda). Its contents are solely the responsibility of the authors and do not necessarily represent the official view of NCRR or NIH. Information on NCRR is available at www.ncrr.nih.gov Information on reengineering the Clinical Research Enterprise can be obtained from http://nihroadmap.nih.gov/ clinicalresearch/

overview-translational.asp

STATEMENT OF INTEREST None declared. 
a)

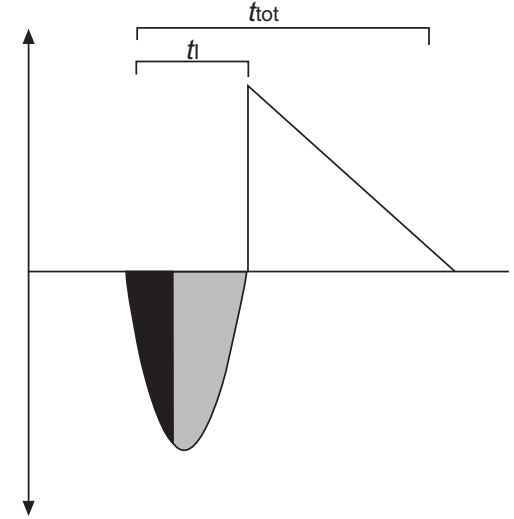

b)

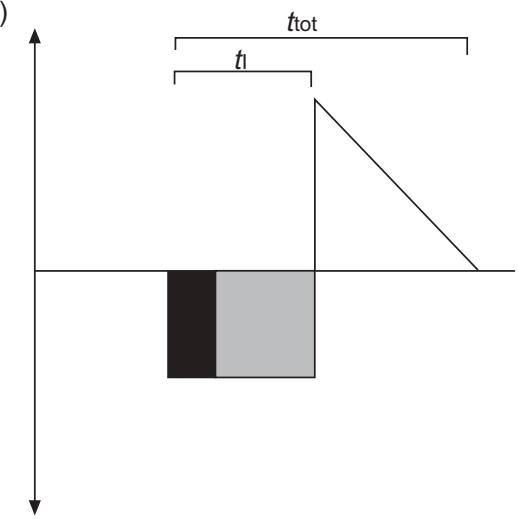

c)

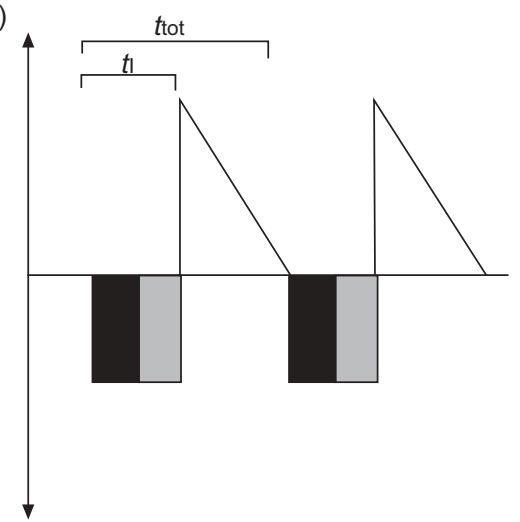

FIGURE 1. a) Normal nonflow-limited breathing compared with b) inspiratory duty cycle (t//ttot) response and c) respiratory frequency (fR) response to upper airway obstruction (UAO). For illustrative purposes, a reduction in mean inspiratory airflow from $300 \mathrm{~mL} \cdot \mathrm{s}^{-1}$ at baseline to $200 \mathrm{~mL} \cdot \mathrm{s}^{-1}$ during UAO was assumed. b) Prolongation of the t// ttot may help maintain alveolar ventilation ( $\left.V^{\prime} A\right)$ during periods of UAO. In contrast, c) increases in fR would increase the portion of dead space ventilation to minute ventilation, thereby lowering $V^{\prime} A$, if tI/ttot remains unchanged. tl: inspiratory time; tot: total respiratory cycle duration. $\mathbb{1}$ : Alveolar volume;

: dead space volume. See also table 1.

\section{MATERIALS AND METHODS}

\section{Conceptual approach}

Although the mechanisms involved in stabilising ventilation in the presence of UAO have not been well defined, UAO is known to increase respiratory drive [19], which normally should increase mean inspiratory flow $(V \mathrm{~T} / \mathrm{t} \mathrm{I})$. However, as the upper airway collapses; such increases in drive can not produce further increase in $V \mathrm{~T} / \mathrm{t} \mathrm{I}$ because inspiratory flow is limited to a maximal level, despite increased effort [23, 24]. Therefore, during periods of inspiratory flow limitation, increases in inspiratory effort (drive) cannot maintain ventilation during sleep. Instead, ventilation can only be preserved by prolonging the $t \mathrm{t} / \mathrm{t}$ tot $[17,18]$, which will maintain and stabilise ventilation during periods of inspiratory flow limitation (fig. 1 and table 1). In contrast, for a given $t I / t$ tot, increases in $f R$ (fig. 1 and table 1 ) would decrease tidal volume $(V \mathrm{~T})$. As $V \mathrm{~T}$ falls, the dead space fraction will increase, and alveolar ventilation $\left(V^{\prime} \mathrm{A}\right)$ will decrease accordingly. Thus, $t \mathrm{I} / t$ tot and $f \mathrm{R}$ responses to a given level of UAO may determine the degree of hypoventilation during sleep. Specifically, as the $t \mathrm{I} / t$ tot increases, an individual can maintain $V^{\prime}$ A which protects them against sleep-disordered breathing, whereas increases in $f R$ may compromise $V^{\prime}$ A and increase the susceptibility to sleepdisordered breathing. $V^{\prime}$ A was calculated by assuming a dead space volume $(V D)$ of $150 \mathrm{~mL}$ and the following equation, in which $V^{\prime} \mathrm{D}$ is dead space ventilation.

$$
V^{\prime} \mathrm{A}=V^{\prime} \mathrm{E}-V^{\prime} \mathrm{D}=\left(V \mathrm{~T} / t_{\mathrm{I}} \times t \mathrm{I} / t_{\text {tot }}\right)-(V \mathrm{D} \times f \mathrm{R})
$$

\section{Study subjects}

In total, 26 healthy volunteers (10 males and 16 females) were initially recruited from the community for a baseline sleep study with no history of snoring or concurrent illness and no evidence of sleep-disordered breathing (apnoea/hypopnoea index $<5$ events $\cdot h^{-1}$ ) or flow limitation ( $<50 \%$ non-REM time). From the group, 10 females were matched to males based on BMI $\left( \pm 3 \mathrm{~kg} \cdot \mathrm{m}^{-2}\right)$ and age $( \pm 5 \mathrm{yrs})$. The study protocol was approved by the Johns Hopkins Bayview Medical Center Institutional Review Board (Baltimore, MD, USA) and all subjects provided written informed consent.

\section{Study methods}

Polysomnography

Standard polysomnography included monitoring of electroencephalograms (C3-A2 and C3-O1), left and right electro-oculograms,

\section{TABLE 1 Ventilatory responses to upper airway obstruction (UAO) compared with normal nonflow-limited (NFL) breathing}

Normal NFL breathing

\begin{tabular}{|c|c|}
\hline$V T / t ı \mathrm{~mL} \cdot \mathrm{s}^{-1}$ & 300 \\
\hline VD mL & 150 \\
\hline$t_{1} / t_{\text {tot }}$ & 0.33 \\
\hline$f R$ breaths $\cdot \min ^{-1}$ & 10 \\
\hline$V^{\prime} E L \cdot \min ^{-1}$ & 5.9 \\
\hline$V^{\prime} D \mathrm{~L} \cdot \mathrm{min}^{-1}$ & 1.5 \\
\hline$V^{\prime} A L \cdot \min ^{-1}$ & 4.4 \\
\hline
\end{tabular}

tI/ttot responses to UAO

fR responses to UAO

tI/tot: inspiratory duty cycle; fR: respiratory frequency; $V T / t t:$ mean inspiratory airflow; VD: dead space volume; V'E: minute ventilation; $V^{\prime} D$ : dead space ventilation; $V^{\prime} A$ : alveolar ventilation. See also figure 1. 


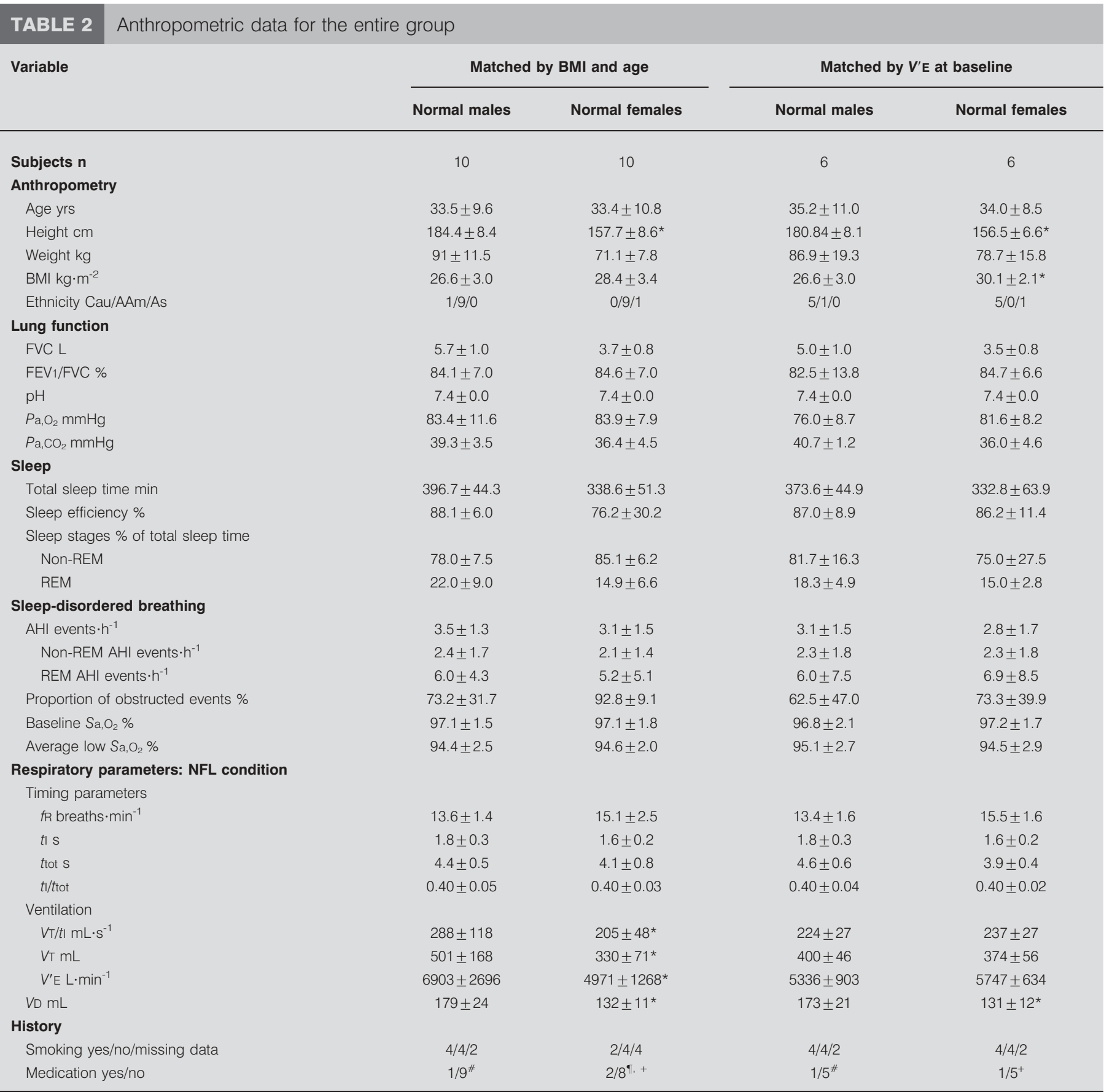

Data are presented as mean \pm SD, unless otherwise stated. BMI: body mass index; V'E: minute ventilation; Cau: Caucasian; AAm: African-American; As: Asian: FVC: forced vital capacity; $F E V 1$ : forced expiratory volume in one second; $\mathrm{Pa}_{2} \mathrm{O}_{2}$ : arterial oxygen tension; $\mathrm{Pa}_{\mathrm{a}} \mathrm{CO}_{2}$ : arterial carbon dioxide tension; $\mathrm{REM}$ : rapid eye movement; AHI: apnoea/hypopnoea index; $\mathrm{Sa}, \mathrm{O}_{2}$ : arterial oxygen saturation; NFL: nonflow limited; fR: respiratory frequency; $t$ : inspiratory time; ttot: total time of respiratory cycle; tI/ttot: inspiratory duty cycle; VT/tI: mean inspiratory airflow; VT: tidal volume; VD: dead space volume. * : Ibuprofen; ": Levoxyl 75 mg; ${ }^{+}$: Claritin. *: p<0.05.

submental electromyogram, ECG (modified V2 lead), arterial oxygen saturation, body position via infrared video cameras, tidal airflow with a pneumotachometer (model 3700A; Hans Rudolph Inc., Kansas City, MO, USA) affixed to a tightfitting nasal mask and nasal pressure $\left(P_{n}\right)$ through a side hole in the nasal mask.
Nasal pressure generator

$P \mathrm{n}$ was controlled by a critical pressure machine, which is a modified continuous positive airway pressure device (ResMed, MAP medicine technology, Martinsried, Germany), specifically designed to apply both negative and positive pressure over a range of -20-20 $\mathrm{cmH}_{2} \mathrm{O}(-1.95-1.95 \mathrm{kPa})$, as previously described $[25,26]$. 


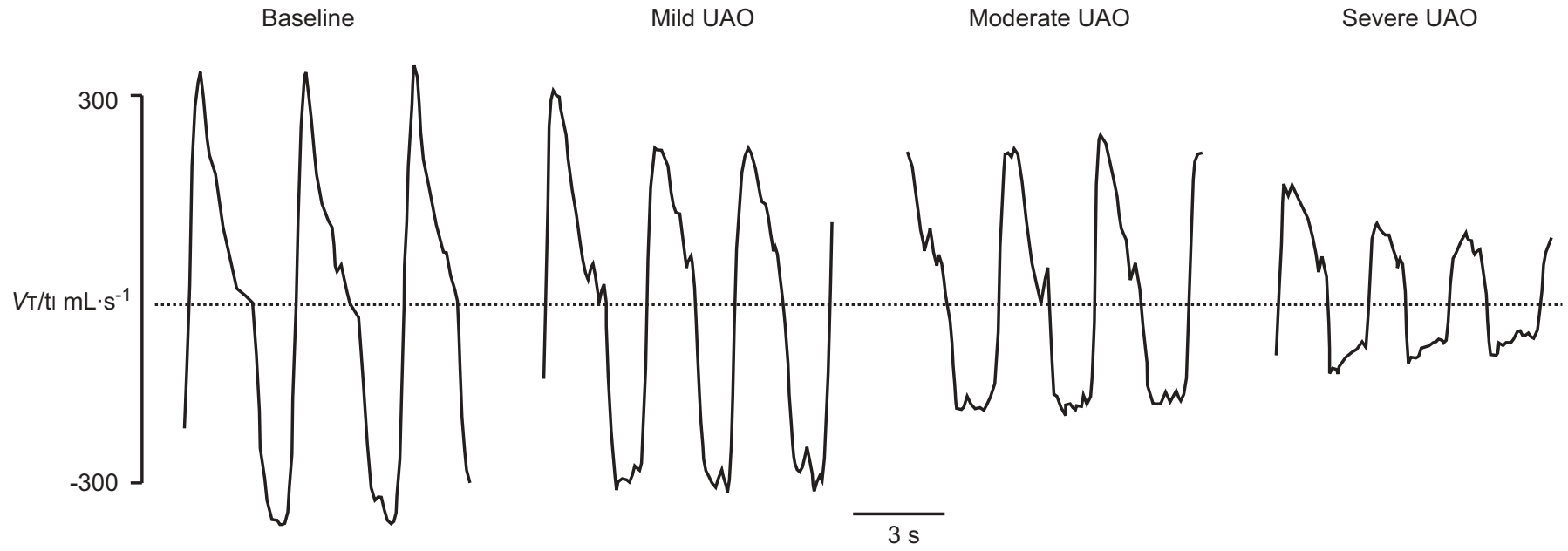

FIGURE 2. Recording example from a male illustrating flow signals and ventilatory parameters at baseline and specific levels of upper airway obstruction (UAO). It should be noted that mean inspiratory airflow $\left(V_{T} / t\right.$ l) deflection represents inhaled flow downward. With decreasing levels of $V_{T} / t t$, inspiratory duty cycle and respiratory frequency increased while minute ventilation decreased progressively. See also table 3.

\section{Study design}

Altering nasal pressure

During wakefulness, individuals were acclimatised to breathing through a nasal mask at a pressure of $6 \mathrm{cmH}_{2} \mathrm{O}$ (holding pressure; $0.59 \mathrm{kPa}$ ). When stable non-REM stage 2 sleep was observed for $\geqslant 3$ min, $P$ n was abruptly lowered by $2 \mathrm{cmH}_{2} \mathrm{O}$ $(0.19 \mathrm{kPa})$ for five breaths or until an arousal occurred. Pn was then returned to holding pressure for $\sim 120 \mathrm{~s}$, and was repeatedly lowered by additional steps of $\sim 2 \mathrm{cmH}_{2} \mathrm{O}$ decrements until airflow ceased. Note, the $P_{n}$ at baseline was lowered from $6 \mathrm{cmH}_{2} \mathrm{O}$ to either 5 or $4 \mathrm{cmH}_{2} \mathrm{O}(0.48$ or $0.38 \mathrm{kPa} ; \mathrm{n}=2$ and $\mathrm{n}=3$, respectively) in selected subjects in order to facilitate sleep onset.

\section{Determination of ventilatory responses to UAO}

Breaths during non-REM sleep were selected from the holding pressure and each pressure drop as described below. During stable breathing at the holding pressure, the last three breaths prior to the first pressure drop were selected for determining ventilatory parameters for nonflow-limited (NFL) breathing during sleep. Each step decrease in $P_{n}$ was first assessed for the presence of inspiratory flow limitation. Breaths two to four of each pressure drop with a stable flow limited breathing pattern were then tabulated, and the degree of UAO was categorised as mild, moderate or severe flow limitation based on $V \mathrm{~T} / t \mathrm{I}$ of $200 \pm$ $25 \mathrm{~mL} \cdot \mathrm{s}^{-1}, 150 \pm 25 \mathrm{~mL} \cdot \mathrm{s}^{-1}$ and $100 \pm 25 \mathrm{~mL} \cdot \mathrm{s}^{-1}$, respectively. For each category, $t \mathrm{I} / \mathrm{ttot}_{\mathrm{t}} \mathrm{fR}, V \mathrm{~T}$ and $V^{\prime} \mathrm{E}$ were calculated. In addition, $V D$ was calculated using $V$ D norms in males and females, as given (in $\mathrm{mL}$ ) by the square of the height (in cm) divided by 189 [27]. $V^{\prime} \mathrm{A}$ was assessed using $V^{\prime} E$ minus $V^{\prime} D$.

\section{Statistical analysis}

Two-way ANOVA for repeated measures and Taguchi's method of post hoc analysis of significance were used for comparing ventilatory responses for each degree of UAO within and between sex groups. Linear regression was utilised to examine the relationship between respiratory timing indices in the moderate UAO condition against BMI and sex. A p-value $<0.05$ was considered statistically significant.

\section{RESULTS}

Anthropometric data, sleep study results, lung function tests and smoking history are shown in table 2 for the entire group matched by BMI and age and a subset matched by $V^{\prime} \mathrm{E}$ $\left( \pm 0.5 \mathrm{~L} \cdot \mathrm{min}^{-1}\right)$ at baseline.

A total of $141 \mathrm{Pn}$ drops with induced UAO were available for analysis, of which 464 flow-limited breaths (six to seven breaths per UAO category) were analysed and compared with 60 normal NFL breaths (three breaths per subject). While $P$ n was similar between the sexes for the baseline NFL condition (females $5.2 \pm 1.6$ versus males $5.8 \pm 1.8 \mathrm{cmH}_{2} \mathrm{O}(0.50 \pm 0.15$ versus $\left.0.56 \pm 0.17 \mathrm{kPa})\right)$,

TABLE 3 Recording example from a male illustrating flow signals and ventilatory parameters at baseline and specific levels of upper airway obstruction (UAO)

\begin{tabular}{|c|c|c|c|c|}
\hline & Baseline & Mild UAO & Moderate UAO & Severe UAO \\
\hline$V \mathrm{~T} / \mathrm{t} \mathrm{I} \mathrm{mL} \cdot \mathrm{s}^{-1}$ & 231 & 196 & 144 & 103 \\
\hline$V^{\prime} E L \cdot \min ^{-1}$ & 5.5 & 5.3 & 4.0 & 3.4 \\
\hline$t_{1} /$ tot & 0.40 & 0.45 & 0.47 & 0.56 \\
\hline$f R$ breaths $\cdot \min ^{-1}$ & 15.9 & 20.3 & 20.8 & 21.1 \\
\hline
\end{tabular}

$V_{T} / t \mathrm{t}$ : mean inspiratory airflow; $V^{\prime} E$ : minute ventilation; $t / /$ tot: inspiratory duty cycle; fR: respiratory frequency. See also figure 2 

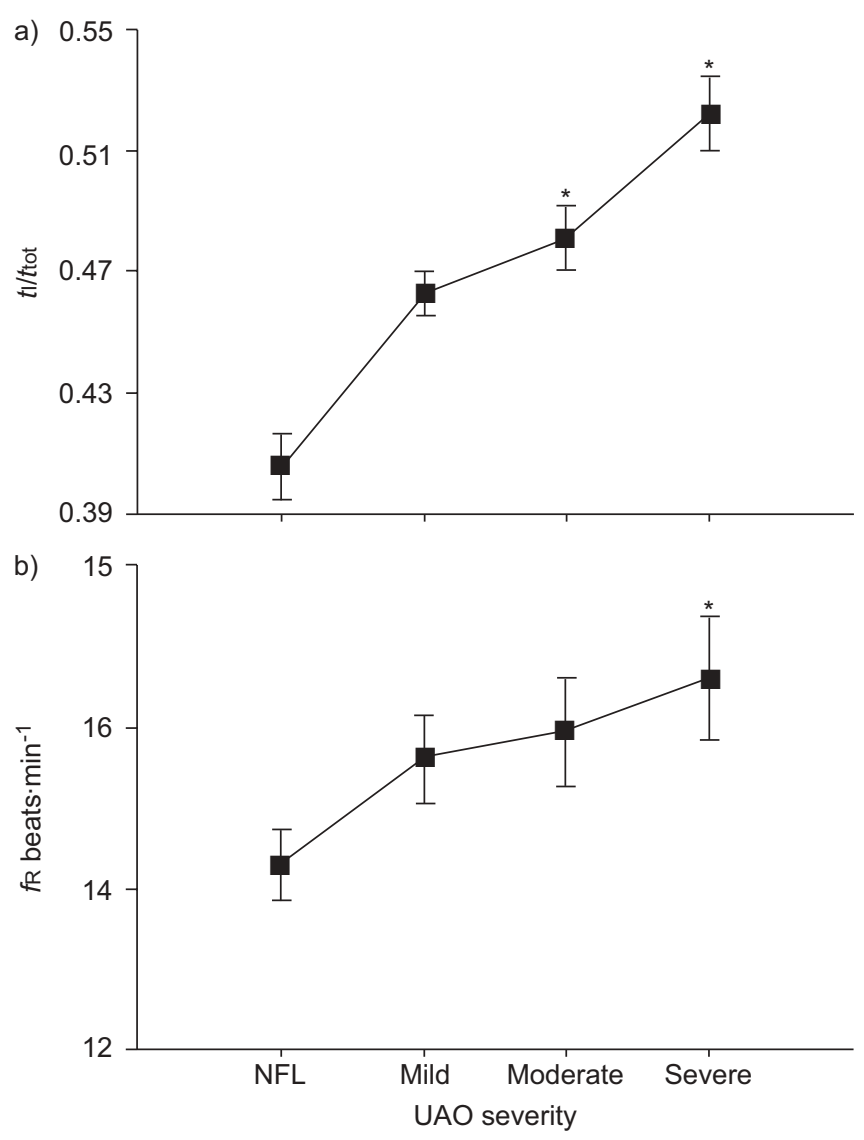

FIGURE 3. The mean \pm SEM of a) inspiratory duty cycle (t//ttot) and b) respiratory frequency $(\mathrm{fR})$ in response to increasing severity (mean inspiratory airflow levels were 200, 150 and $100 \mathrm{~mL} \cdot \mathrm{s}^{-1}$ for mild, moderate and severe upper airway obstruction (UAO), respectively) of $U A O$ in normal individuals. *: $p<0.05$ compared with nonflow-limited (NFL) breathing.

$P$ n was slighty lower $(\mathrm{p}<0.05)$ during all flow-limited categories in females (mild $-1.5 \pm 3.6$ versus $0.2 \pm 4.3 \mathrm{cmH}_{2} \mathrm{O}(-0.14 \pm 0.35$ versus $0.02 \pm 0.42 \mathrm{kPa})$; moderate $-2.1 \pm 4.0$ versus $1.0 \pm 2.6 \mathrm{cmH}_{2} \mathrm{O}$ $(-2.0 \pm 0.39$ versus $0.10 \pm 0.25 \mathrm{kPa})$; and severe $-2.8 \pm 4.9$ versus $-0.1 \pm 2.6 \mathrm{cmH}_{2} \mathrm{O}(-0.27 \pm 0.48$ versus $-0.01 \pm 0.25 \mathrm{kPa})$ for females versus males, respectively).

\section{Baseline ventilatory parameters during NFL breathing}

The baseline respiratory parameters of the subjects are presented in table 2. Respiratory timing indices (inspiratory time $(t \mathrm{I})$, total time of respiratory cycle (ttot) and $t \mathrm{I} / \mathrm{ttot})$ were similar in both sexes in the NFL state. In contrast, $V \mathrm{~T} / t \mathrm{I}$ and $V^{\prime} \mathrm{E}$ during non-REM sleep were $\sim 40 \%$ lower in females compared with males, indicating a lower ventilatory demand in BMI and age-matched females compared with males during stable nonREM sleep. It should be noted that the anatomic $V D$ was also lower in females compared with males in both groups.

\section{Interindividual variability of ventilatory responses of UAO}

Figure 2 and table 3 illustrate $V^{\prime} \mathrm{E}$ and timing responses to experimentally induced $\mathrm{UAO}$ in one individual. While $V^{\prime} \mathrm{E}$ declined with increasing degrees of UAO, both $t \mathrm{I} / \mathrm{t}$ tot and $f \mathrm{R}$ increased progressively. Pooled data of all individuals in figure 3 demonstrate that increasing levels of UAO led to a
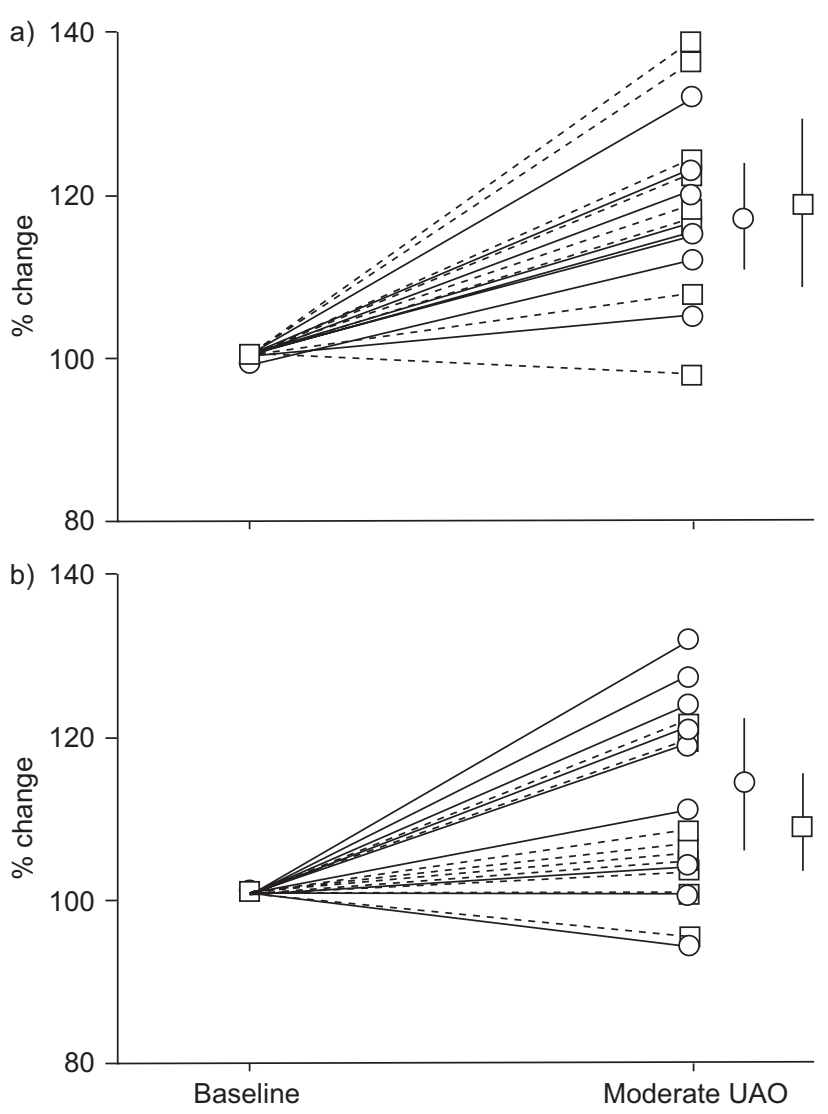

FIGURE 4. The percentage change in a) inspiratory duty cycle and b) respiratory frequency from baseline $(100 \%$ to moderate upper airway obstruction $(\mathrm{UAO})$ ) are shown for each male $(\square)$ and female $(\bigcirc)$ and, on the right of each graph, are presented as mean \pm SEM for each sex.

dose-dependent response of $t \mathrm{I} / t$ tot and $f \mathrm{R}$. Figure 4 shows that individual responses of $t \mathrm{I} / \mathrm{t}$ tot and $f \mathrm{R}$ to moderate UAO varied markedly from $97 \%$ to $140 \%$ and $95 \%$ to $135 \%$, respectively.

As outlined previously, it was hypothesised that an increase in $t \mathrm{I} / t$ tot, rather than $f \mathrm{R}$, will improve $V^{\prime} \mathrm{E}$. Therefore, quartiles of $t \mathrm{I} / \mathrm{t}$ tot and $f \mathrm{R}$ responses to moderate $\mathrm{UAO}$ of individuals were determined (fig. 4). Quartiles for $t \mathrm{I} / \mathrm{t}$ tot and $f R$ for all individuals did not differ by age, sex or BMI at baseline. In each quartile, $V^{\prime} E$ compared with the mean $V^{\prime} E$ of the entire group was calculated. In figure 5, $V^{\prime} \mathrm{E}$ for individuals in each quartile for $t \mathrm{I} / t_{\text {tot }}$ and $f \mathrm{R}$ responses is illustrated. Compared with the mean $V^{\prime} \mathrm{E}$ of $4,279 \mathrm{~mL} \cdot \mathrm{min}^{-1}$ for the entire group, individuals with a low $t \mathrm{I} / \mathrm{t}$ tot response $(0.44)$ had $\sim 400 \mathrm{~mL}$ lower $V^{\prime} E$ compared with those with a high $t \mathrm{I} / t_{\text {tot }}$ response (0.51) who had a $500 \mathrm{~mL}$ higher ventilation $(\mathrm{p}<0.01)$ compared with the entire group. In contrast, $f R$ responses did not contribute to an increase in $V^{\prime} \mathrm{E}$.

\section{Sex differences in ventilatory responses to UAO}

Several post hoc analyses were conducted to determine the influence of sex on ventilatory responses to UAO. In the first analysis, all males and females were included and timing indices and $V^{\prime} \mathrm{E}$ were determined in response to decreasing absolute levels of mean $V \mathrm{~T} / t \mathrm{I}$. While $t \mathrm{I} / t_{\text {tot }}$ responses were 


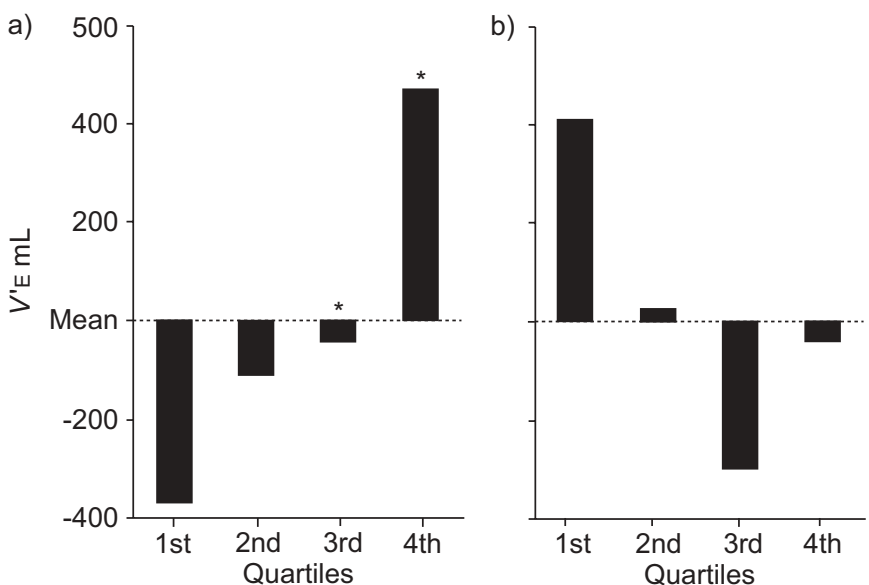

FIGURE 5. The effect of increasing levels of a) inspiratory duty cycle and b) respiratory frequency responses on minute ventilation $\left(V^{\prime} E\right)$ compared with the mean $V^{\prime} E$, which was $4,279 \mathrm{~mL} \cdot \mathrm{min}^{-1}$ of the entire group during moderate upper airway obstruction. *: $p<0.05$. similar between males and females, $f R$ had a greater increase in females compared with males (fig. 6). Nevertheless, $V^{\prime}$ E during $\mathrm{UAO}$ was similar between sexes, despite marked differences in $V^{\prime} \mathrm{E}$ at baseline.

As previously noted (table 2), the $V \mathrm{~T} / \mathrm{tI}$ at baseline was $80 \mathrm{~mL}$ lower in females. Thus, categories of flow limitation based on absolute levels of inspiratory airflow represented a smaller per cent reduction in $V \mathrm{~T} / t \mathrm{I}$ in females compared with males. Therefore, two additional post hoc analyses were conducted to account for absolute differences in $V \mathrm{~T} / t \mathrm{I}$ at baseline between males and females. First, $V \mathrm{~T} / t \mathrm{I}$ and $V^{\prime} \mathrm{E}$ was matched in a subgroup of females $(n=6)$ and males $(n=6$; table 2$)$, which produced similar percentage reductions in inspiratory airflow from baseline to mild ( $89 \%$ to $84 \%$ ), moderate $(67 \%$ to $63 \%$ ) and severe $(45 \%$ to $42 \%)$ levels of UAO. This approach produced similar responses between females and males in $t \mathrm{I} / \mathrm{t}$ tot, $f \mathrm{R}$ and $V^{\prime} \mathrm{E}$.

Secondly, the severity of UAO was defined by a per cent reduction in $V \mathrm{~T} / t \mathrm{I}$ from baseline for all subjects. Comparing females and males, the present authors demonstrated that responses in $t \mathrm{I} / \mathrm{t}$ tot
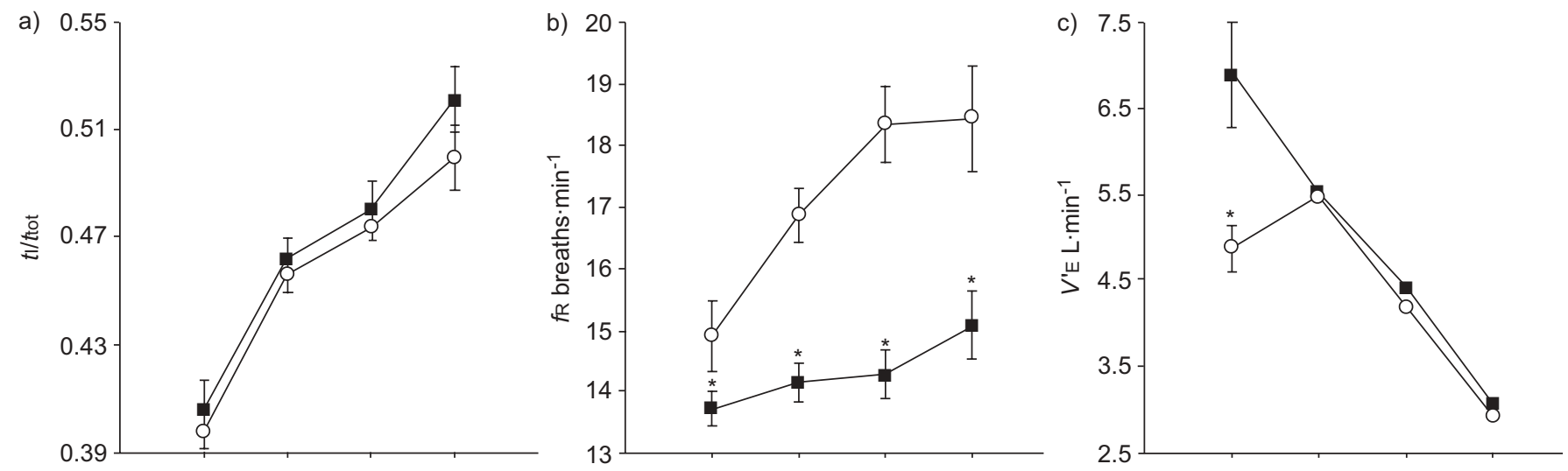

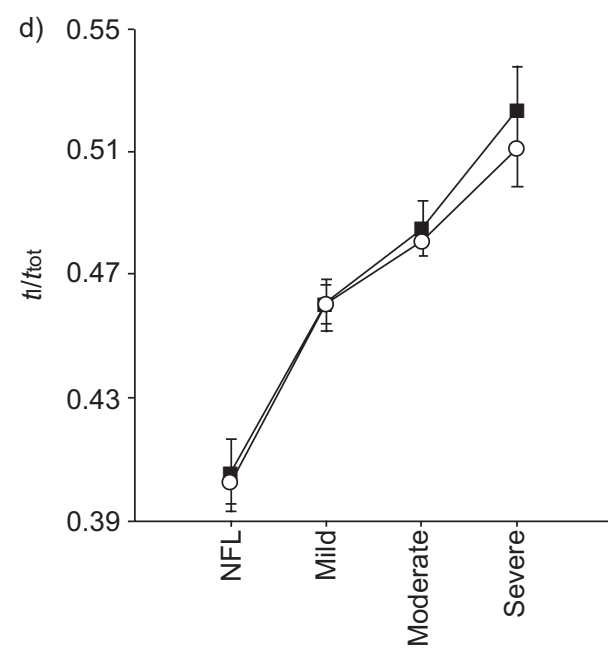

UAO severity

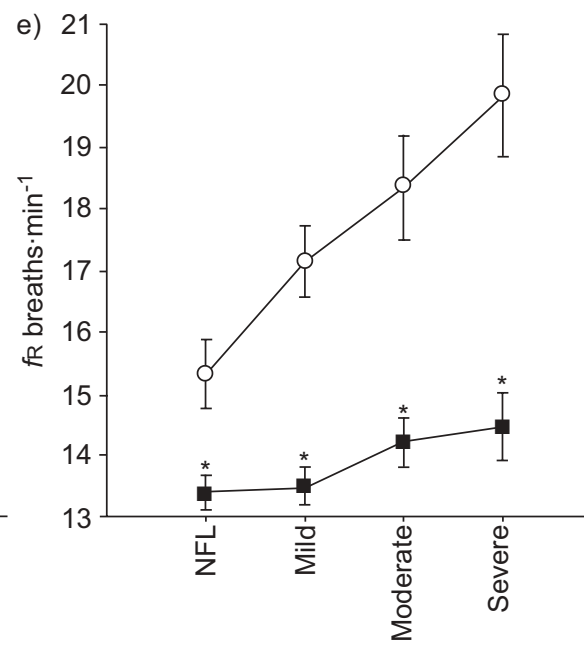

UAO severity

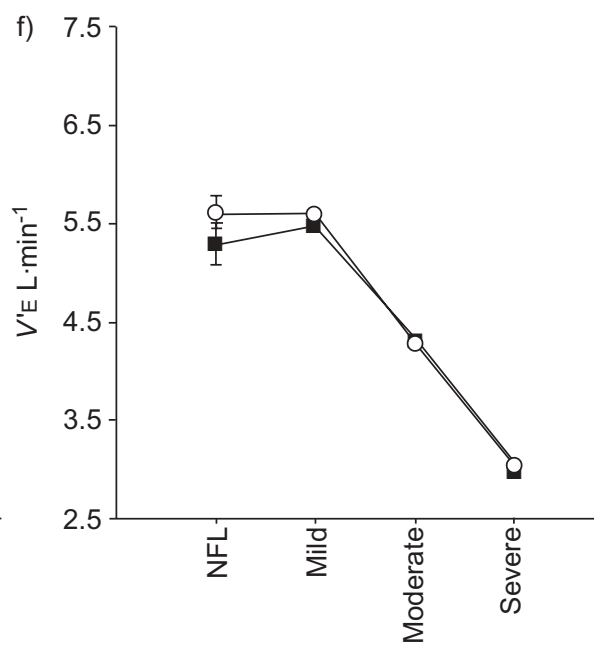

UAO severity

FIGURE 6. The mean \pm SEM $a$ and d) inspiratory duty cycle (t//tot), b and e) respiratory frequency (fR) and $c$ and f) minute ventilation ( $\left.V^{\prime} E\right)$ for males ( and females $(O)$ matched by body mass index and age $(a-c ; n=20)$ and matched by baseline $V^{\prime} E(d-f ; n=12)$. Differences were determined by two-way ANOVA. NFL: nonflow limited; UAO: upper airway obstruction. *: $p<0.05$ 

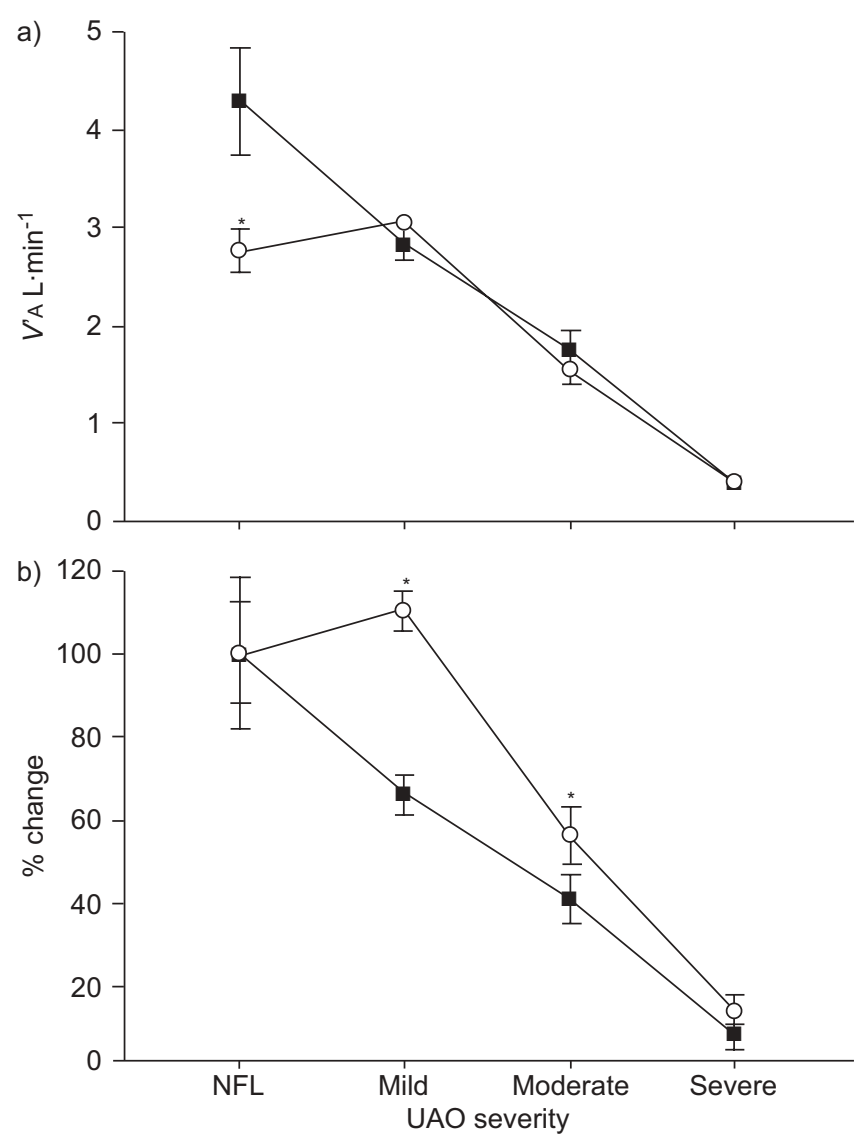

FIGURE 7. a) Alveolar ventilation ( $V^{\prime} A$; mean \pm SEM) for males $(\boldsymbol{\square})$ and females $(\bigcirc)$. b) Relative percentage changes in $V^{\prime} A$ compared with baseline (100\%). Differences were determined by a paired t-test. NFL: nonflow limited. *: $p<0.05$.

and $f R$ were similar to the above approaches, indicating that sex differences in ventilatory responses persist regardless of the method used for defining the exposure to UAO (flow limitation; see online supplementary material).

\section{Alveolar ventilation}

As outlined previously, a high $f \mathrm{R}$ under conditions of a fixed inspiratory airflow and unchanged $t \mathrm{I} / \mathrm{t}$ tot should increase $V^{\prime} \mathrm{D}$ and thereby lower $V^{\prime}$ A. Since females had a higher $f R$ at all severities of UAO and $t \mathrm{I} / \mathrm{t}$ tot was similar between sexes, one would expect lower $V^{\prime} \mathrm{A}$ in females. However, males and females had comparable levels of $V^{\prime}$ A at all severities of UAO (fig. 7), indicating that a lower $V \mathrm{D}$ offset the higher $f \mathrm{R}$ in females (table 2).

Females also had markedly lower $V^{\prime} \mathrm{E}$ at baseline, indicating a lower ventilatory demand during non-REM sleep. In contrast, females had similar $V^{\prime}$ A at all severities of UAO compared with males (fig. 7a). Relative to baseline (fig. 7b), females preserved $V^{\prime}$ A better than males during mild and moderate flow limited conditions.

\section{$B M I$ effect on ventilatory responses}

To explore the influence of BMI on ventilatory responses to $\mathrm{UAO}$ in males and females, timing responses during conditions of moderate UAO $\left(V \mathrm{~T} / \mathrm{tI}_{\mathrm{I}} 150 \pm 25 \mathrm{~mL} \cdot \mathrm{s}^{-1}\right)$ were analysed using linear regression analysis with BMI and sex as independent variables. Marked differences in respiratory timing responses in both males and females were observed across the spectrum of BMI. In males, neither the $f \mathrm{R}$ nor $t \mathrm{I} / \mathrm{t}$ tot responses varied significantly with BMI. In contrast, females increased the absolute difference and percentage change in $f R$ with increasing BMI. Specifically, an increase in BMI of $10 \mathrm{~kg} \cdot \mathrm{m}^{-2}$ was associated with an increase of 5 breaths $\cdot \mathrm{min}^{-1}$ and a $30 \%$ change from baseline $(\mathrm{p}<0.01$ for both).

\section{DISCUSSION}

The acute effects of UAO on respiratory patterns during sleep were examined. During periods of inspiratory airflow limitation, there was a dose-dependent increase in $t \mathrm{I} / \mathrm{t}$ tot and $f \mathrm{R}$ in response to increasing levels of UAO. Heterogeneity in these responses led to variable degrees of ventilatory compensation to UAO. In particular, increases in the $t \mathrm{I} / t_{\text {tot, }}$ not $f \mathrm{R}$, helped to maintain ventilation and stabilise breathing acutely. Moreover, responses in the $t \mathrm{I} / \mathrm{t}$ tot were independent of sex and BMI; however, the female sex and obesity were associated with a greater response in $f R$. Thus, UAO constitutes a unique load on the respiratory system, and the respiratory timing responses determine the ability to stabilise ventilation and compensate for UAO during sleep.

\section{Timing responses to UAO}

In the current study, brief periods of UAO elicited compensatory increases in the $t \mathrm{I} / t$ tot and $f \mathrm{R}$. This prolongation of $t \mathrm{I} / \mathrm{t}$ tot and $f R$ was dose-dependent and instantaneous, suggesting that upper airway and pulmonary mechanoreceptors, rather than chemoreceptors, mediated these immediate responses to UAO [28-33]. The increase in $t \mathrm{I} / t_{\text {tot }}$ should help to stabilise $V^{\prime} \mathrm{E}$ at any given level of UAO, as described by the following equation $[17,18,20]$, which was imposed experimentally.

$$
V^{\prime} \mathrm{E}=t \mathrm{I} / t_{\text {tot }} \times V \mathrm{~T} / t \mathrm{I}
$$

Under conditions of $\mathrm{UAO}$, the $V \mathrm{~T} / \mathrm{tI}$ approximates the peak inspiratory airflow rate during inspiratory airflow limitation. In the current study, compensatory increases in $t \mathrm{I} / \mathrm{t}$ tot were associated with greater degrees of ventilatory compensation, as reflected by greater increases in $V^{\prime} \mathrm{E}$ (fig. 5). In contrast, increases in $f R$ would be expected to decrease tot and $t \mathrm{I}$ proportionally (fig. 1 and table 1 ), thereby leaving $t \mathrm{I} / t_{\text {tot }}$ and $V^{\prime} \mathrm{E}$ unchanged. Thus, UAO is a unique load for which $V^{\prime} \mathrm{E}$ is independent of $f \mathrm{R}$ at any given level of $t \mathrm{I} / t$ tot and $V \mathrm{~T} / t \mathrm{I}$.

It is intriguing that $t \mathrm{I} / t$ tot and $f \mathrm{R}$ responses to $\mathrm{UAO}$ varied markedly among subjects. This variability in timing responses may be related to differences in metabolic rate, which is known to vary widely between individuals $[34,35]$. At the moderate flow-limited condition, the increases in $t \mathrm{I} / \mathrm{t}$ tot varied markedly among individuals, ranging from $7 \%(0.39-0.42)$ to $48 \%(0.39-$ 0.57 ; fig. 4). Similarly, $f R$ response varied substantially at moderate levels of UAO. It has been previously demonstrated that the $t \mathrm{I} / \mathrm{t}$ tot response to hypercapnia is an intermediate physiological phenotype linked to mouse chromosome 5 [17]. Thus, $t \mathrm{I} / t_{\text {tot }}$ and $f \mathrm{R}$ responses to $\mathrm{UAO}$ may represent constitutive traits that determine the individual's ability to compensate for a given degree of UAO during sleep. 


\section{Sex differences in ventilatory responses to UAO}

Timing responses

While the $t \mathrm{I} / \mathrm{t}$ tot response to UAO was similar between the sexes, $f R$ increased more in females than males. As outlined previously (fig. 1 and table 1), under conditions of unchanged $t \mathrm{I} / t_{\text {tot, }} V^{\prime} \mathrm{D}$ will increase as $f \mathrm{R}$ rises, and the magnitude of this increase will be determined by the subject's VD. An increase in $f R$ would have little impact on $V^{\prime} \mathrm{D}$ if the $V \mathrm{D}$ is negligible, but will increase the $V^{\prime} \mathrm{D}$ markedly if the $V \mathrm{D}$ comprises a large proportion of the $V \mathrm{~T}$. VD was considerably lower in females than males $(132 \pm 11$ versus $179 \pm 24 \mathrm{~mL})$, thereby minimising the impact of elevations in $f R$ on $V^{\prime} D$ in females. Thus, a lower $V \mathrm{D}$ makes females relatively tolerant to a rise in $f R$ during periods of UAO.

\section{Ventilation}

UAO produced similar reductions in $V^{\prime} \mathrm{E}$ and $V^{\prime} \mathrm{A}$ in males and females. Nevertheless, the relative per cent change in $V^{\prime}$ A from baseline was less in females than males (fig. 7). $V^{\prime}$ A tracks metabolic rate during sleep [35], which is $\sim 30 \%$ lower in females than males due to body composition and stature [3439]. At comparable levels of UAO, females are less likely to hypoventilate than males. Thus, both a lower ventilatory demand and lower $V \mathrm{D}$ in females are likely to make females less susceptible to ventilatory instability during periods of UAO.

\section{Limitations}

There are several limitations to be considered. First, the analyses of timing responses were limited to acute periods of UAO. Responses to sustained periods of UAO might differ from acute conditions due to differences in the chemical control of ventilation and upper airway neural and mechanical control [15, 40,41]. Secondly, VD was estimated rather than directly measured. The present authors' attempts to directly measure $V D$ with the Fowler technique $[42,43]$ demonstrated a high inter- and intra-rater variability. Therefore, estimates of $V D$ were used based on anthropometric data, which appears to be more reliable in subjects without underlying lung diseases. Finally, the current authors did not consider controlling the impact of oral contraceptives or menstrual phase on timing responses. Hormonal differences may explain some of the variability in timing responses in females. Nevertheless, males had a similar variability in timing responses, making the present authors suspect that hormones did not account for variations in timing responses in females, but may explain the greater $f R$ response in females compared with males.

\section{Implications}

The present authors have shown that timing responses to UAO allowed for the segregation of individuals based on their propensity to preserve ventilation or to hypoventilate in the face of UAO. Crisp intermediate phenotypes such as these are required to probe for the genetic basis of obstructive sleep apnoea susceptibility. Moreover, the respiratory pattern may predict the susceptibility and expression of sleep-disordered breathing independent of the upper airway properties. First, diseases of the lungs and chest wall produce resistive and elastic loads to the respiratory system, which impact $t \mathrm{I} / \mathrm{t}$ tot and $f R[44,45]$. Because $V \mathrm{~T} / t \mathrm{I}$ responses during UAO are limited (fixed), compensation to defend ventilation are primarily dependent on responses of the $t \mathrm{I} / \mathrm{t}$ tot and the baseline $f R$. Further work is required to examine the role of elastic and restrictive loads on the degree of hypoventilation during periods of UAO compared with normal breathing. Secondly, individuals who have an increased metabolic rate (pregnancy) or $V \mathrm{D}$ (lung diseases) may be susceptible to hypoventilation if compensatory increases in $t \mathrm{I} / \mathrm{t}$ tot are limited and fail to increase $V^{\prime}$ A. Thus, variations in $t \mathrm{I} / t$ tot and $f \mathrm{R}$ may explain disturbances in gas exchange across a spectrum of sleepdisordered breathing aetiologies.

In summary, the present findings indicate that upper airway obstruction elicits specific respiratory responses that may serve as quantitative intermediate traits for obstructive sleep apnoea and suggest that these factors may play a role in sex differences in the expression of sleep-disordered breathing.

\section{ACKNOWLEDGEMENTS}

The current authors would like to thank S.L. Kamsheh, L.A. Frame and S.B. Squier (Johns Hopkins University, Baltimore, MD, USA) for their contributions to the present study, which included technical support and help in the preparation of tables and figures.

\section{REFERENCES}

1 Gleadhill IC, Schwartz AR, Schubert N, Wise RA, Permutt S, Smith PL. Upper airway collapsibility in snorers and in patients with obstructive hypopnea and apnea. Am Rev Respir Dis 1991; 143: 1300-1303.

2 Gold AR, Marcus CL, Dipalo F, Gold MS. Upper airway collapsibility during sleep in upper airway resistance syndrome. Chest 2002; 121: 1531-1540.

3 Schwartz AR, Smith PL, Wise RA, Bankman I, Permutt S. Effect of positive nasal pressure on upper airway pressureflow relationships. J Appl Physiol 1989; 66: 1626-1634.

4 Young T, Peppard PE, Gottlieb DJ. Epidemiology of obstructive sleep apnea: a population health perspective. Am J Respir Crit Care Med 2002; 165: 1217-1239.

5 Jordan AS, McEvoy RD. Gender differences in sleep apnea: epidemiology, clinical presentation and pathogenic mechanisms. Sleep Med Rev 2003; 7: 377-389.

6 Redline S, Kump K, Tishler PV, Browner I, Ferrette V. Gender differences in sleep-disordered breathing in a community-based sample. Am J Respir Crit Care Med 1994; 149: 722-726.

7 Guilleminault C, Partinen M, Hollman K, Powell N, Stoohs R. Familial aggregates in obstructive sleep apnea syndrome. Chest 1995; 107: 1545-1551.

8 Schwab RJ. Genetic determinants of upper airway structure that predispose to obstructive sleep apnea. Respir Physiol Neurobiol 2005; 147: 289-298.

9 Schwab RJ, Pasirstein M, Kaplan L, et al. Family aggregation of upper airway soft tissue structures in normal subjects and patients with sleep apnea. Am J Respir Crit Care Med 2006; 173: 453-463.

10 Redline S, Tishler PV. Familial influences on sleep apnea. In: Saunders NA, Sullivan CE, eds. Sleep and Breathing. 2nd Edn. New York, Marcel Dekker Inc., 1994; pp. 363-377. 
11 Patel SR. Shared genetic risk factors for obstructive sleep apnea and obesity. J Appl Physiol 2005; 99: 1600-1606.

12 Palmer LJ, Buxbaum SG, Larkin EK, et al. Whole genome scan for obstructive sleep apnea and obesity in AfricanAmerican families. Am J Respir Crit Care Med 2004; 169: 1314-1321.

13 Redline S, Tishler PV, Tosteson TD, et al. The familial aggregation of obstructive sleep apnea. Am J Respir Crit Care Med 1995; 151: 682-687.

14 King ED, O'Donnell CP, Smith PL, Schwartz AR. A model of obstructive sleep apnea in normal humans. Role of the upper airway. Am J Respir Crit Care Med 2000; 161: 1979-1984.

15 Patil SP, Schneider H, Marx JJ, Gladmon E, Schwartz AR, Smith PL. Neuromechanical control of upper airway patency during sleep. J Appl Physiol 2007; 102: 547-556.

16 Jordan AS, Wellman A, Heinzer RC, et al. Mechanisms used to restore ventilation after partial upper airway collapse during sleep in humans. Thorax 2007; 62: 861-867.

17 Schneider H, Patil SP, Canisius S, et al. Hypercapnic duty cycle is an intermediate physiological phenotype linked to mouse chromosome 5. J Appl Physiol 2003; 95: 11-19.

18 Younes M. Contributions of upper airway mechanics and control mechanisms to severity of obstructive apnea. Am J Respir Crit Care Med 2003; 168: 645-658.

19 Stoohs R, Guilleminault C. Snoring during NREM sleep: respiratory timing, esophageal pressure and EEG arousal. Respir Physiol 1991; 85: 151-167.

20 Tagaito Y, Schneider H, O'Donnell CP, Smith PL, Schwartz AR. Ventilating with tracheal gas insufflation and periodic tracheal occlusion during sleep and wakefulness. Chest 2002; 122: 1742-1750.

21 Pichard LE, Patil SP, Gladmon E, Smith PL, Schwartz AR, Schneider $\mathrm{H}$. Women have a greater ventilatory responses to upper airway obstruction than men. Conf Proc IEEE Eng Med Biol Soc 2004; 5: 3878-3880.

22 Krishnan V, Pichard LE, Patil S, Schwartz AR, Smith PL, Schneider $\mathrm{H}$. Gender differences in ventilatory response to inspiratory flow limitation during non rapid eye movement (NREM) sleep. American Thoracic Society 2007; 3: A197.

23 Smith PL, Wise RA, Gold AR, Schwartz AR, Permutt S. Upper airway pressure-flow relationships in obstructive sleep apnea. J Appl Physiol 1988; 64: 789-795.

24 Smith PL, Schwartz AR, Gauda E, Wise R, Brower R, PermuttS. The modulation of upper airway critical pressures during sleep. In: Issa FG, Surratt PM, Remmers JE, eds. Sleep and Respiration. New York, Wiley-Liss, 1990; pp. 253-260.

25 Eastwood PR, Szollosi I, Platt PR, Hillman DR. Collapsibility of the upper airway during anesthesia with isoflurane. Anesthesiology 2002; 97: 786-793.

26 Patil SP, Punjabi NM, Schneider H, O'Donnell CP, Smith PL, Schwartz AR. A simplified method for measuring critical pressures during sleep in the clinical setting. Am J Respir Crit Care Med 2004; 170: 86-93.

27 Miller MR, Crapo R, Hankinson J, et al. General considerations for lung function testing. Eur Respir J 2005; 26: 153-161.

28 Chow CM, Xi L, Smith CA, Saupe KW, Dempsey JA. A volume-dependent apneic threshold during NREM sleep in the dog. J Appl Physiol 1994; 76: 2315-2325.

29 Coleridge HM, Coleridge JCG. Reflexes evoked from tracheobronchial tree and lungs. In: Fishman AP,
Cherniack NS, Widdicombe JG, Geiger SR, eds. Handbook of Physiology. Section 3: The Respiratory System. Volume II Control of Breathing, Part 1. Baltimore, Waverly Press Inc., 1986; pp. 395-429.

30 Iber C, Simon P, Skatrud JB, Mahowald MW, Dempsey JA. The Breuer-Hering reflex in humans. Effects of pulmonary denervation and hypocapnia. Am J Respir Crit Care Med 1995; 152: 217-224.

31 Kimoff RJ, Sforza E, Champagne V, Ofiara L, Gendron D. Upper airway sensation in snoring and obstructive sleep apnea. Am J Respir Crit Care Med 2001; 164: 250-255.

32 Leevers AM, Simon PM, Xi L, Dempsey JA. Apnoea following normocapnic mechanical ventilation in awake mammals: a demonstration of control system inertia. J Physiol (Lond) 1993; 472: 749-768.

33 Manchanda S, Leevers AM, Wilson CR, Simon PM, Skatrud JB, Dempsey JA. Frequency and volume thresholds for inhibition of inspiratory motor output during mechanical ventilation. Respir Physiol 1996; 105: 1-16.

34 Aitken ML, Franklin JL, Pierson DJ, Schoene RB. Influence of body size and gender on control of ventilation. J Appl Physiol 1986; 60: 1894-1899.

35 White DP, Weil JV, Zwillich CW. Metabolic rate and breathing during sleep. J Appl Physiol 1985; 59: 384-391.

36 Fontvieille AM, Rising R, Spraul M, Larson DE, Ravussin E. Relationship between sleep stages and metabolic rate in humans. Am J Physiol 1994; 267: E732-E737.

37 Webb P, Hiestand M. Sleep metabolism and age. J Appl Physiol 1975; 38: 257-262.

38 Ferraro R, Lillioja S, Fontvieille AM, Rising R, Bogardus C, Ravussin E. Lower sedentary metabolic rate in women compared with men. J Clin Invest 1992; 90: 780-784.

39 Kreider MB, Biskirk ER, Bass DE. Oxygen consumption and body temperatures during the night. J Appl Physiol 1958; 12: 361-366.

40 Schneider H, Boudewyns A, Smith PL, et al. Modulation of upper airway collapsibility during sleep: influence of respiratory phase and flow regimen. J Appl Physiol 2002; 93: 1365-1376.

41 Schwartz AR, O'Donnell CP, Baron J, et al. The hypotonic upper airway in obstructive sleep apnea: role of structures and neuromuscular activity. Am J Respir Crit Care Med 1998; 157: 1051-1057.

42 Kars AH, Bogaard JM, Stijnen T, de Vries J, Verbraak AF, Hilvering $C$. Dead space and slope indices from the expiratory carbon dioxide tension-volume curve. Eur Respir J 1997; 10: 1829-1836.

43 Fowler WS, Comroe JH. Lung function studies. I. The rate of increase of arterial oxygen saturation during the inhalation of $100 \% \mathrm{O}_{2}$. J Clin Invest 1948; 27: 327-334.

44 Milic-Emili J, Zin WA. Breathing responses to imposed mechanical loads. In: Fishman AP, Cherniack NS, Widdicombe JG, Geiger SR, eds. Handbook of Physiology. Section 3 - The Respiratory System, Vol. II. Bethesda, American Physiological Society, 1986; pp. 751-769.

45 Iber C, Berssenbrugge A, Skatrud JB, Dempsey JA. Ventilatory adaptations to resistive loading during wakefulness and non-REM sleep. J Appl Physiol 1982; 52: 607-614. 